\title{
Unlucky, bad and the space in between: why criminologists should think more about responsibility
}

Peter Raynor (accepted version, prior to proofing and typesetting: see end for details)

'The simple things you see are all complicated' (The Who 1966)

In the early 1970s I was working as a probation officer, supervising offenders in the community and providing information about defendants to magistrates and judges in order, supposedly, to help them to make appropriate sentencing decisions. In the course of this work, to cut a long story short, I met a few people who committed crimes in a very deliberate and planned way, for personal gain or advantage, in circumstances where they clearly had every opportunity to avoid crime and to meet their needs or satisfy their desires in legitimate ways. Much more often, however, I was dealing with people who did not seem to be showing such a high degree of control and self-direction in their offending. Some were experiencing extreme poverty; some were the products of disorganised families where there was little opportunity for normal social learning; some were offending while their self-control was impaired through alcohol or drugs; some suffered a range of physical or mental illnesses (though not usually of a kind which compelled them to offend); some had difficulty controlling the impulse to throw a punch or place yet another bet. Many had difficulty seeing beyond the short-term situation in which they offended, while others lacked understanding of how their behaviour affected others, particularly their victims. Some were victims themselves, living with the consequences of early abuse, while others seemed trapped into lifestyles in which offending was normal, and previous offending had closed off most legitimate opportunities. This brief list does not exhaust the commonly encountered antecedents of offending: criminologists know about, and workers in criminal justice 
encounter a wide range of crimes, of people who get themselves into trouble and of accounts (both professional and lay) which seek to explain how crime occurs. Most of the time, however, I seemed to be dealing with people who were clearly not compelled to commit offences, but who also found it very difficult to avoid doing so, and were often under circumstantial pressures which made offending appear, at least in the short term, to be a viable choice.

I also met, less frequently, people whose behaviour clearly resulted from mental illness and was beyond their control. However, between these cases and the other rare situations in which offences had been committed without any obvious pressures at all, simply because somebody wanted something they could not legitimately have, were most of the people with whom I worked. In other words, most people who were offending seemed to be doing so in situations when it would be possible but difficult to avoid doing so, given their circumstances, their limited material and personal resources, and their established habits of thinking and behaviour. Occasionally, if a homicide was involved, the law might recognise extreme situational pressures or mental stresses by deploying the concept of diminished responsibility, but this approach was not available for routine everyday offences. In between the extremes of, on one side, freely chosen selfish antisocial crimes and, on the other side, actions which genuinely could not be avoided (in other words, between bad and unlucky) lay a broad territory which many offenders inhabited most of the time. For them, offending was a choice, but an unwise one, in circumstances which they usually had not chosen and which offered few good alternatives. Many offenders regretted their offending, and hoped to avoid it in future, when given the opportunity to reflect on it in calmer circumstances. How far, I wondered, should we blame such people for making these bad choices? Or was all offending simply the product of forces beyond the offenders' own control? 


\section{Crimes and diseases}

While I was still involved in practical work with people who were in trouble with the law, the philosopher Antony Flew published his short book 'Crime or Disease?' (Flew 1973) which set out to address some of the same questions. His concern was to refute the arguments of deterministic psychiatrists and psychologists who held that since all behaviour was causally determined, none of it could be regarded as freely chosen. Responsibility, guilt, blame, desert were all pre-scientific concepts and illusory. More recently, since some changes in the brain which are relatively reliable precursors of behaviour can now be observed and measured, the standard-bearer for such claims has been neuroscience (for example, 'Free will, as we normally understand it, is an illusion' write Greene and Cohen (2006: 221)), but well before the 1970s it had been observed that brain injuries and brain surgery could alter behaviour, moods and even beliefs. In addition electrical stimulation of some parts of the brain could sometimes produce movements which the subject believed to be voluntary. Flew was, to say the least, unconvinced by claims that psychological determinism could abolish choice and responsibility, and his arguments bear revisiting in the context of more recent controversies.

Diseases, argues Flew, and in particular mental diseases, are distinguished by the fact that they create incapacities and reduce our ability to act as we choose. In the absence of disease (which, to avoid circularity, needs to be evidenced by something other than the behaviour we are trying to explain) the capacity for choice exists, based on the capacity to exercise free will. Our experience of free will is based on a 'familiar difference' between what Flew calls 'moving' (i.e. voluntary action) and 'motion', which is involuntary movement such as a knee jerk reflex or a sneeze. The difference is illustrated by the contrast between 'I moved my arm' and 'my arm moved (although I didn't move it)'. Flew argues that such 'familiar 
differences' are undeniable: 'no discovery . . . could ever abolish familiar differences, or invalidate distinctions founded solely upon such differences' (Flew 1973: 103). In addition he points out, surely correctly, that the commonsense and ordinary language meanings of phrases like 'I did it of my own free will' are not metaphysical claims to be an uncaused cause, but are simply accounts of agency in relation to movings (e.g. 'I moved my arm of my own free will') or statements about the absence of coercion (e.g. 'I did it of my own free will, nobody forced me'). He argues that even if full determinism exists (and it is not clear to me what would count as conclusive evidence for this), choices can be causes and have consequences without themselves being uncaused. I would add that reasons for action can be explanatory ('this is how I came to do this') or justifying ('this is why I thought this was the right thing to do') and that these can produce different reasons without invalidating each other.

These arguments made fascinating reading for a young probation officer, dealing every day with issues arising from people's imperfect control over their own actions or their poor choices about them. In retrospect it also seems clear that more recent deterministic claims arising from neuroscience are not logically different from those made by some psychiatrists and psychologists in the 1970s, and Flew's arguments still work. However, they applied most clearly to fully free actions (moving) and unfree behaviour (motion). Some thought was still needed about what they meant for the broad range of intermediate cases of choices made under pressures which fall short of coercion, and impulses potentially subject to control which were not controlled. What did they imply about the culpability of people whose offending seems to be as much a natural consequence of their circumstances as a deliberate choice? These concerns can be illustrated by considering some of the everyday difficulties of interpreting and allocating responsibility and blameworthiness in criminal justice. 


\section{Social and psychological information in sentencing}

A hundred students are listening to a lecture on punishment and rehabilitation. The lecturer introduces a sentencing exercise, based on cases in his past experience: a male burglar, 19 years old,, with two previous convictions for theft which resulted in fines, has been convicted of breaking into a house while the owners were away, stealing a computer, TV and jewellery worth $£ 1000$. He was arrested trying to sell the jewellery. What sentence would the students give him? The vast majority opt for an immediate custodial sentence. Then they are given some more information: his parents separated when he was four years old, he was brought up in local authority care until he was 16 , he had a job in a shop but lost it when the shop went bankrupt. He has no educational qualifications and poor literacy, and is technically homeless so he receives limited welfare payments. Asked to vote again, far fewer students choose the immediate custodial sentence. A few more facts are added: he was drunk when he did the burglary, he drinks every day with his friends, half his income (when he has one) goes on drink and drugs, and he has not finished paying his outstanding fines. The majority choice now becomes a period of supervision by the probation service combined with assistance to reduce his use of alcohol and drugs. The social information appears to have had two effects: not only has it provided information about needs which can be addressed through appropriate sentencing to reduce the probability of further offences, it has also reduced the severity of the proposed sentence. It has affected the students' views of how much punishment the offender deserves, and of how blameworthy he is for the current offence.

Something like this often seemed to be the impact of the hundreds of social enquiry reports (now called pre-sentence reports) which I prepared about the background, behaviour and personality of defendants appearing in court (see Raynor 1980). In many cases it seemed that 
the background information was influencing perceptions of an offender's blameworthiness as well as the sentencer's thinking about what results a sentence might be able to achieve. Adding information derived from neuroscience to the available knowledge about an offender might assist understanding of internal as well as external constraints (for example a history of brain injury or concussive accident might make it more difficult for some people to control their tempers or to resist other kinds of impulses) but it does not appear that this kind of information has a different logical force from the kinds of social and personal information already mentioned. In particular it does not abolish responsibility unless it demonstrably amounts to compulsion. Short of compulsion, such information might affect judgement about degrees of blameworthiness, but responsibility remains. Pardo and Patterson (2013) have convincingly argued against claims that knowledge derived from neuroscience invalidates legal views of responsibility.

Theories of punishment distinguish between the retributive rationale, which relates the amount of punishment to what the seriousness of the offence deserves, and the consequentialist rationale which aims to change the behaviour of the offender or other potential offenders. In practice these two rationales are often combined: the overall size of the sentence can be determined and limited by desert, while the content can be designed to rehabilitate and to reduce the probability of further offences. (In fact Swedish law requires both elements to be present in sentencing: see Asp 2010.) It appears that social, contextual and psychological information can be relevant to both types of sentencing, and can influence our perceptions of blameworthiness, although there is often room for argument about what sort of influence is appropriate. For example, do previous convictions increase the seriousness of the current offence or simply reduce the mitigation from which a first offender would expect to benefit (see Von Hirsch 2010)? A useful discussion of moral and legal 
responsibility in different circumstances is provided by Kennett (2001) who sets out to construct a 'common sense moral psychology' by examining the differences between behaviour arising from recklessness, weakness and compulsion.

Only compulsion negates responsibility, and needs to be demonstrated by convincing evidence. The reckless person is responsible for failing to take reasonable care and for not resisting an impulse which could have been resisted; the weak person may be unable to exercise control in the present, but can be criticised for failing to take actions in the past which could have been taken, and which could have avoided the current situation in which weakness leads to offending. The role of drink and drugs in the sentencing exercise described above would fall under this heading. Self-control can be 'synchronic', exercised in the present, or 'diachronic', exercised in the past to avoid problems later. In either case 'our ascriptions of psychological capacities and competences, including the capacity for selfcontrol, do not require or gain justification from the truth or falsity of some general proposition in physics or neurophysiology' (Kennett 2001: 164). It is clear that many offenders have difficulties with self-control, and/or difficult circumstances in which to try to exercise it. Social and psychological information at the point of sentencing can help to throw light on both these conditions, without negating responsibility except in cases of compulsion.

\section{Predictable offending}

One other way in which neuroscience might be held to threaten our everyday concepts of free choice and responsibility concerns the predictability of offending. If observation of brain states allows us to identify reliable precursors of offending, so that we can predict with a fair degree of accuracy that further offending will occur, does this mean that the choice to offend is predetermined and therefore not free, so that no-one could be held responsible for it? This 
is, of course, simply a variant of the argument considered earlier in this chapter, that caused choices cannot be free. However, it also raises some interesting questions in relation to predictability. The second major use of social and psychological information in criminal justice, in addition to its use in sentencing, is in the assessment of offenders' needs and likely behaviour. A substantial literature on the subject, supported by research on hundreds of thousands of subjects, has grown up over the last 30 years. Research and practice have shown that knowledge of a few key facts about an offender can enable a prediction about the probability of future offending which will be accurate at a much better than chance level. Strictly speaking it is a prediction of the proportion of a group of similar offenders that will offend rather than a prediction about an individual, but it still yields a risk score, usually in the form of a percentage, indicating the probability for an individual member of the group.

The earliest successful reconviction predictors in Britain were developed in the early 1990s by statisticians who used regression analysis of criminal records to calculate the probability of future offending by establishing statistical relationships with age, sex, previous offending and the nature of the current offence (Copas 1992). These are known to criminologists as 'static' risk factors because they cannot be altered retrospectively at will. They also tell us nothing about what might need to be changed to reduce the chance of further offending. For this we need a different approach known as 'risk/need' assessment, which was developed mainly in Canada and began to be adopted in Britain in the mid-1990s (Raynor 2007). This approach mixes some static risk factors with assessments of the social circumstances and personality of the offender, which are mostly 'dynamic' risk factors, also known as criminogenic needs, and are in principle subject to change. Many forensic psychologists now look at what are known as the 'Central Eight' risk factors (Bonta and Andrews 2017): these are, in brief, a history of offending, procriminal attitudes, procriminal associates, anti-social 
personality pattern, adverse family or marital circumstances, problems around school or work, substance abuse, and absence of pro-social leisure or recreational activities. This kind of assessment provides both an estimate of the risk of reoffending and guidance about what would need to change to reduce the risk, which is helpful for those involved in offender management or rehabilitation. Levels of accuracy achieved by these methods, if properly applied, are typically within a few points either side of $75 \%$ correct prediction, with greater accuracy available for very high or very low scorers (for example, people with adverse circumstances, including drug abuse, and a long history of frequent offending are very likely to continue, whilst people in middle age leading broadly satisfactory lives with no history of offending are quite unlikely to start).

There are interesting arguments in the literature about the proper use of risk assessment: for example, parole boards are rightly concerned about who might be too dangerous to release, but extended sentences for high risk offenders which exceed the normal proportionate sentence for the current offence have been frequently criticised. Risk/need assessment can be used to inform more effective rehabilitation services rather than simply to calibrate levels of coercion (Raynor 2016). However, it has never been suggested by developers or practitioners of these methods that the fact that an offence can be predicted means that it is not subject to choice. What is being predicted is how that choice will be exercised. Advocates of risk assessment methods have not usually regarded them as deterministic: some of their most determined critics (Case and Haines 2009) have argued that they can produce an expectation in the minds of professionals which leads to self-fulfilling prophecies, turning some children into 'crash test dummies' being accelerated towards disaster, but even they do not regard this as inevitable, and they suggest a number of strategies to avoid it. The emergence of new prediction methods based on neuroscience, if this should happen, would not alter the fact that 
what is being predicted is a choice to offend. In Flew's terms this is 'moving' not 'motion'. It should also be noted that as risk/need assessment is designed to support rehabilitation and to help people to reduce their offending, it actually aims to falsify its own predictions. Far from predetermining offences, it seeks to inform intervention to prevent them.

In some circumstances we have other less technical ways of predicting offences. For example, we might notice that an offender with a history of violence is becoming tense, breathing hard, speaking loudly, going red in the face, scowling and clenching his fists. It is not hard to make a prediction based on these indicators. Presumably observation of brain states, if the subject would permit this, would yield some similar precursors of violence. For Kennett, this would be a case in which self-control is very difficult to exercise because the current impulse to violence is overwhelmingly strong, but the subject might be held responsible for failing to exercise diachronic self-control before allowing himself to become so angry or so aggressive. He would bear some responsibility for the situation unless he could be shown to have a genuine inability to resist impulses. This inability would have to be observable in a range of situations, not just in the current predicament, and would raise questions about incapacity and potential need for treatment. The relevant difference, for Kennett, is between being incapable of self-control, and having a capacity for self-control which on this occasion is not being used. In practice, some people can find themselves in this kind of state without being aware of it, or not aware until it is too late to regain control. The anger management training which is offered to some offenders is designed to help them to recognise the signs of becoming angry and aggressive, and to apply various self-control techniques such as relaxation and appropriate self-talk to interrupt the process and regain control. Kennett argues that the exercise of self-control is primarily a cognitive process, and it is interesting that one of the most successful recent developments in the rehabilitation of 
offenders has been the development of offending behaviour programmes designed usually by psychologists and based on cognitive-behavioural principles. It is worth considering what might be learned from these about behavioural change, coercion and choice.

\section{Programmes, learning and autonomy}

Offending behaviour programmes (Hollin and Palmer 2006) are structured and replicable sequences of exercises and other work carried out with offenders (usually in prison or on probation) to help them to understand and control their behaviour. They are usually designed by psychologists, based on social learning theory and using cognitive-behavioural methods, and when implemented correctly (which they often are not) they typically result, on average, in reductions in reoffending of about ten percentage points below predicted levels, or below levels achieved by similar offenders dealt with in different ways (Lösel 1995). In Britain they mainly take the form of group programmes, and when delivered in the community attendance is required by a Court order, though in practice attendance has sometimes been poor. The skills which programmes aim to teach are typically problem solving, interpersonal skills, selfmanagement of emotion, appreciation of other people's point of view, and making decisions by stopping and thinking rather than on impulse. Variations have been developed for special groups of offenders such as those with drug or alcohol problems, sex offenders, domestic violence offenders and others but virtually all have the same rationale in social learning theory, and the same approach to systematic design supported by manuals to ensure that they are implemented as faithfully as possible.

Probation staff reactions to the introduction of programmes were mixed. Some welcomed them, while others were put off by the apparent concentration on thinking skills when they preferred to see crime as a consequence of social disadvantage. Some disliked the 
standardisation inherent in putting large numbers of people through the same programmes, and more recent designs have included more adaptability to individual offenders. Many of the early reservations about programmes were gathered together in book form (Mair 2004). A few probation staff disliked the idea of programmes altogether, perhaps seeing them as similar to brainwashing or to the fictitious coercive therapy inflicted on Alex in Stanley Kubrick's film of Anthony Burgess's novel ‘A Clockwork Orange' (Burgess 1962): in other words, they saw programmes as a process which limited and reduced offenders' freedom, in effect reducing crime by creating incapacities. Whilst temporary incapacitation is among the proper goals for custodial punishment, it did not fit with traditional concepts of probation, which in those days was an agreement entered into between the probationer and the sentencing court. (The requirement of consent to a probation order was not abolished until 1997: see Raynor 2014.) However, the experience of programme members who made progress during programmes seemed mainly to reflect the designers' social learning goals. For example, two of the graduates of an early programme in Wales made the following comments to a researcher (Maurice Vanstone, reported in Lucas, Raynor and Vanstone 1992):

'It's helped me to solve problems and get them through to people better. Prevents me from jumping off the handle. I listen more, I think about problems more and discuss things. It takes a lot of stress off my head because I listen to others.'

'It's made me realise . . It's learnt me to put myself in other people's places if they'd been burgled . . Guilty's the word. It's out of order. It's opened my mind and I look at a subject from all different angles .. Not just jumping the gun. With problems I can clear them up more easily' (Lucas, Raynor and Vanstone 1992: 29). 
Similar comments were made by many of the 64 programme members interviewed. Here we see examples of reduced impulsiveness, more systematic problem solving with awareness of alternatives, more appreciation of the feelings of victims and other people generally, and an improved ability to seek and use help from others. Reduction of impulsiveness, which can be understood as strengthening of self-control, is one of the most common findings from evaluations of offending behaviour programmes. The quotations do not seem to come from people who feel their freedom has been reduced: on the contrary, they show an awareness of more capacity to encounter life and choose how to lead it. They also raise another kind of question about responsibility: if people who lack self-direction, self-control and relevant knowledge get into trouble, they should logically be seen as less to blame then people who have acquired these skills. Perhaps (other things being equal, which they often are not) the successful programme graduate is more blameworthy for the next lapse than somebody who has not had the opportunity to learn responsible behaviour. In other words, some of the mitigation which might be applied to the offender who has limited social competence may not be available to somebody who has learned to have more choice about offending. Knowledge can enable choice, and freedom of choice implies accountability for choices.

\section{Desistance and choice}

One final branch of contemporary criminology which has implications for our understanding of choice and responsibility is the emerging field of desistance studies (for example Farrall et al. 2014). Desistance theorists aim to throw light on the process of giving up offending, based mainly on qualitative studies of offenders' own accounts rather than on the literature of 'what works' and effective intervention. Crime emerges from desistance studies neither as a simple product of the environment nor as a choice made free from environmental pressures, and this 
accords with our everyday experience that we do make choices, but we often do not choose the circumstances in which we have to make them. Other insights from desistance studies, which have had some effect on the way criminal justice practitioners approach rehabilitation, include evidence (summarised in Maguire and Raynor 2006) that for persistent offenders, desistance is a process not an event; it is multicausal; it involves obstacles, mistakes, relapses - 'a zig-zag process', and it often requires development of social and individual 'capital'. It is complete when a non-criminal identity and way of life are firmly established ('primary' becomes 'secondary' desistance), and is facilitated by social bonds to pro-social others, including partners, and parental responsibility. It often requires access to help, and motivation to make use of it.

The relationship between environmental influences and individual choice is often expressed in social science as a relationship between structure and agency, and agency appears to play a significant role in desistance. Two studies illustrate this particularly clearly. In a study of released prisoners in Canada, the researchers concluded that established patterns of thinking, and in particular beliefs about their own capacity to overcome obstacles, played a significant role in distinguishing those who stayed out of trouble from those who reoffended:

'In the case of criminal behaviour, factors in the social environment seem influential determinants of initial delinquency for a substantial proportion of offenders . . . but habitual offending is better predicted by looking at an individual's acquired ways of reacting to common situations' (Zamble and Quinsey 1997: 146-7).

In another influential study, based on interviews with a group of probationers (Maruna 2001) The researcher summed up his findings as follows: the desisting offender had a 'strong sense 
that he or she is in control of his or her destiny. Whereas active offenders . . s seemed to have little vision of what the future might hold, desisting interviewees had a plan and were optimistic that they could make it work' (Maruna 2001: 147).

From this kind of study it appears that desisting offenders see themselves as more free and as having more choices than continuing offenders, who are likely to see themselves as victims of circumstances. The more self-directing desisters are not best understood simply as conforming, but as choosing and building a non-offending identity and status. This is reminiscent of the condition of 'orthonomy' (Kennett 2001) in which people are both autonomous and seek to choose actions which can be justified according to accepted standards of conduct.

\section{Conclusion}

I have argued in this chapter that although recent developments in neuroscience may add considerably to our understanding of human actions, they cannot sufficiently support arguments which deny the existence of choice or responsibility. In other words they cannot undermine or deny our direct experience of human actions. If the hard determinist claims were true, our concept of human action would be fatally compromised in a way which would deny the possibility of an action and fundamentally question our experience of what it means to be human. In short, as Antony Flew put it, 'determinist presuppositions cannot disprove' familiar differences between voluntary and involuntary movements, and between choosing to do something and being coerced. In ordinary usage, doing something of my own free will usually means simply that I was not coerced. Similar arguments are advanced by Kenny (1978), and Strawson (1968) pointed out that our whole vocabulary of communication about 
our own actions and other people's, including blame, resentment, approval and all similar concepts, would become meaningless if determinism ruled out individual responsibility.

In addition, it is not clear how deterministic claims arising from neuroscience are new or original. Flew's particular targets were deterministic psychiatrists such as Karl Menninger, who believed that offending was not a matter of choice but was psychodynamically determined (Menninger 1968) - a product of 'unconscious mental forces' (Blum 1968). The work of behaviourist psychologists such as B. F. Skinner, who had little interest in 'unconscious mental forces', has also been used as the basis for deterministic arguments against free will and responsibility (as the title of Skinner's best known book implies: Skinner 1971). Arguments based on observed brain states appear not to differ fundamentally from the earlier rehearsals of similar arguments: the empirical basis for identifying the brain states may be more convincing than that for 'unconscious mental forces' but it is not clear (except in cases of properly diagnosed mental illness or incapacity) that they are any more capable of eliminating choice and responsibility than other methods of predicting the risk of offending which were discussed earlier in this chapter. A better understanding of the antecedents of our actions, or even of our likely future actions, does not mean we have no control over them or accountability for them.

There is therefore little doubt that neuroscience leaves our common-sense and ordinarylanguage use of responsibility and culpability largely intact. However some circumstances which commonly occur in criminal justice call for a realistic view of responsibility based on how far people could reasonably have been expected to exercise control over their behaviour. Offenders who are popularly seen as fully responsible for their harmful behaviour ('bad') often see themselves as victims of circumstances with little choice ('unlucky'). A realistic 
view usually lies somewhere in between. For example, some offenders may have lost control of their actions in the present, but can reasonably be held to account for failure to exercise control in the past which would have interrupted the sequence of events which led to the current offence, if opportunities for such control (Kennett's 'diachronic' self-control) did in fact exist in the past. In addition, much rehabilitative work with offenders is directed towards increasing their control over their own behaviour: for example, reducing impulsiveness by teaching people to think before acting (an example of Kennett's 'synchronic' self-control). Self-control can also be understood as self-direction or autonomy: rehabilitation often increases an offender's freedom of choice rather than aiming to reduce it.

Finally, the challenge of neuroscience may not be catastrophic for our common-sense moral thinking, but it certainly suggests that criminologists should think more systematically about questions of responsibility. In the many cases where offending is made more likely by restricted opportunities not to offend, or by a lifetime subject to anti-social influences beyond the offender's control, some criminologists will see social causation as removing responsibility from the individual offender, as if responsibility must rest either with the individual or with society. However, the arguments reviewed in this chapter suggest that responsibility is often shared, as Kennett argues in relation to disadvantaged offenders. The history of disadvantage does not simply mitigate, it suggests that society's expectation that the offender should avoid further offending needs practical support, both in relation to the individual offender through opportunities and resources for desistance, and in relation to potential offenders in general through social policy. Rehabilitation can be society's contribution to support the desisting offender, in a specific instance of the more general social contract between the state and its citizens (see Raynor and Robinson 2009). Most criminologists' advocacy of rehabilitative and re-integrative justice can only gain from a 
realistic view of responsibility for offending. In holding offenders to account, we should also be aware of the responsibility of Government and other social institutions when their choice of policies increases or fails to address avoidable criminogenic risks which make people more likely to choose to offend. As Kennett puts it, 'holding someone responsible, to whatever extent, need not and should not rule out compassion for their plight or an acknowledgement of any contribution made by society to their predicament' (Kennett 2001: 198). Current policy often fails this test.

\section{References}

Asp, P. (2010) 'Previous convictions and proportionate punishment under Swedish law' in Roberts, J. and Von Hirsch, A. eds. Previous Convictions at Sentencing. Oxford: Hart Publishing 207-226.

Blum, G. S. (1968) Psychodynamics: the Science of Unconscious Mental Forces. Belmont: Wadsworth Publishing.

Bonta, J. and Andrews, D. (2017) The Psychology of Criminal Conduct. Sixth edition. London: Routledge.

Burgess, A. (1962) A Clockwork Orange. London: Heinemann.

Case, S. and Haines, K. (2009) Understanding Youth Offending. Cullompton: Willan. 
Copas, J. B. (1992) Statistical analysis for a risk of reconviction predictor. Report to the Home Office. University of Warwick: unpublished.

Farrall, S., Hunter, B., Sharpe, G. and Calverley, A. (2014) Criminal Careers in Transition: the social context of desistance from crime. Oxford: Oxford University Press.

Flew, A. (1973) Crime or Disease? London: Macmillan.

Greene, J. and Cohen, J. (2006) 'For law, neuroscience changes nothing and everything' in Zeki, S. and Goodenough, O. eds. Law and the Brain. Oxford: Oxford University Press 207226.

Hollin, C. and Palmer, E. eds. (2006) Offending Behaviour Programmes. Chichester: Wiley.

Kennett, J. (2001) Agency and Resposibility . Oxford: Oxford University Press.

Kenny, A. (1978) Freewill and Responsibility. London: Routledge.

Lösel, F. (1995) 'The efficacy of correctional treatment: a review and synthesis of metaevaluations', in McGuire, J. (ed.) What Works: reducing reoffending. Chichester: Wiley.

Lucas, J., Raynor, P. and Vanstone, M. (1992) Straight Thinking On Probation one year on. Bridgend: Mid Glamorgan Probation Service. 
Maguire, M. and Raynor, P. (2006) 'How the resettlement of prisoners promotes desistance from crime: or does it?' Criminology and Criminal justice 6(1) 19-38.

Mair, G. ed. (2004) What Matters in Probation. Cullompton: Willan.

Maruna, S. (2001) Making Good. Washington: American Psychological Association.

Menninger, K. (1968) The Crime of Punishment. New York: Viking Press.

Pardo, M. S. and Patterson, D. (2013) Minds, Brains and Law. Oxford: Oxford University Press.

Raynor, P. (1980) 'Is there any sense in social inquiry reports?' Probation Journal 27(3) 7884.

Raynor, P. (2007) 'Risk and need assessment in British probation: the contribution of LSI-R', Psychology, Crime and Law 13(2) 125-138.

Raynor, P. (2014) 'Consent to probation in England and Wales: how it was abolished, and why it matters'. European Journal of Probation 6(3) 296-307.

Raynor, P. (2016) 'Three narratives of risk: corrections, critique and context' in Trotter, C., Mcivor, G. and McNeill, F. eds. Beyond the Risk Paradigm in Criminal Justice. Basingstoke: Palgrave, 24-45. 
Skinner, B. F. (1971) Beyond Freedom and Dignity. New York: Knopf.

Strawson, P. F. (1968) 'Freedom and Resentment' in Strawson, P. F. ed. Studies in the Philosophy of Thought and Action. Oxford: Oxford University Press 71-96.

The Who (1966) Substitute. Reaction Records.

Von Hirsch, A. (2010) 'Proportionality and progressive loss of mitigation: further reflections' in Roberts, J. and Von Hirsch, A. eds. Previous Convictions at Sentencing. Oxford: Hart Publishing 1-16.

Zamble, E. and Quinsey, V. (1997) The Criminal Recidivism Process. Cambridge: Cambridge University Press.

(This is the accepted version, prior to proofreading and typesetting. The version of record, with some changes to format and style of references, appears as Chapter 9 in DonnellyLazarov, B. with Patterson, D. and Raynor, P. eds. Neurolaw and Responsibility for Action, to be published by Cambridge University Press in April 2018.) 